\title{
Derek Kennet
}

\section{Chapter 6 \\ Periodisation and Dating of the Sequence}

Before outlining the periodisation of the stratigraphic sequences from Paithan, it is necessary to say a few words about how it was achieved and to put this into the context of the way in which periodisation has been carried out on other excavated Early Historic sites in India.

\section{Problems with the periodisation of Early Historic sites in India}

At Paithan, as at many excavated Early Historic sites, several trenches were excavated in different locations across the site. It should not be expected that the occupational history of each trench will be the same. As can be seen by observing any modern town or village anywhere in the world, some areas of a settlement may be left open and abandoned whilst adjacent areas are densely occupied. This situation may change in succeeding periods so that areas once built up turn to wasteland whilst areas once unused are built up. This seems obvious, but nonetheless, the way in which the stratigraphic sequences of many Early Historic excavations in India have been periodised implies a belief that all parts of each site will share a similar occupational and depositional history and that all periods of occupation will be present in all trenches.

Nevasa is a good illustration of this. An examination of the Nevasa report, published in 1960, shows that a four-period occupational history has been imposed on all of the trenches excavated at the site, including trenches $\mathrm{I}, \mathrm{X}$ and $\mathrm{Y}$, which are located at a considerable distance from the main trenches $(\mathrm{A}-\mathrm{H})$, despite the fact that a Qutubshahi coin and sherds of glazed ware were found in the levels of trench I that are otherwise ascribed to the 'Indo-Roman' period (Sankalia et al. 1960: 65, 204, 344-345). This is because the periodisation has failed to take into consideration that there may be 'voids' in the occupation history of some areas of the site and this hascaused layers to be forced into periods where they do not belong, grouping material of different dates into the same period.
There are deeper problems with the periodisation of Nevasa. This is shown in Table 6.1, which is based on a detailed reading of the published report. It shows the occurrence of glazed wares that are not themselves specifically discussed by the excavators in the publication. It can be seen that the glazed wares and 'celadons', all of which date to the 11th/12th century and later to judge by the published photographs, occur in layers that have been attributed by the excavators to much earlier periods. For example, there are two sherds of glazed warefrom layers attributed to Period IV (150-50 BC), which, although anomalous, may simply be intrusive. More worrying is the much larger quantity that was found in layers attributed to Period V, the so-called 'Indo-Roman' period, that is dated from $50 \mathrm{BC}$ to $\mathrm{AD} 200$. This is indicative of some fundamental problems with the periodisation of the Nevasa sequence and demonstrates the importance of taking a holistic and quantified view of the pottery, small find and coin assemblages and of applying rigorously the rule of terminus post quem. These problems are further compounded by the fact that the pottery from Nevasa is published by period rather than by layer. This makes it impossible to disentangle the pottery sequence from the flawed periodisation.

Table 6.1: Occurrence of glazed wares in the Nevasa sequence. Note that only one sherd of glazed ware is listed on page 339 of the report from Period IV, but two are listed on page 345.

\begin{tabular}{lrrrrr}
\hline Nevasa Period & Glaze a & Glaze b & Glaze c Celadon & Total \\
\hline VI (AD 1400-1700) & 45 & 10 & & 5 & 60 \\
\hline V (50 BC-AD 200) & 14 & 5 & 4 & 7 & 30 \\
\hline IV (150-50 BC) & & 1 & 1 & & 2 \\
\hline
\end{tabular}

Similar problems can be shown to exist in the periodisation of many of the published Early Historic sites in India, although there is no space here to go into these in further detail. Nonetheless, much of the archaeological chronology of Early Historic India is still based on the periodisation of such sites. This chronology may have many serious flaws and is in need of a full-scale review. 
A further problem is that quite often, the occurrence of a single coin, for example a Satavahana coin, is enough for a layer or for an entire period to be attributed to the Satavahana period. The rule of terminus post quem is thereby ignored. This rule states that any datable find, such as a coin, indicates that the layer within which it is contained was deposited at the time of the date of the coin or at any time since that date. Thus, a Satavahana coin in a layer indicates only that the layer was deposited in the Satavahana period, or at any time since. Indeed, it is well established that Satavahana coins continued incirculation into much later periods (Sircar 1974: 18; Shastri 1992: 291-292). The same concept applies equally to pottery; a single sherd of Northern Black Polished ware (NBP) or Red Polished ware (RPW) does not necessarily indicate that the layer within which it is contained is datable to the period of circulation of that ware. It may be that the sherd is residual and the layer may have been deposited at a much later date, often several centuries later. Quantification of the pottery assemblage can go some way towards resolving this issue by highlighting 'outliers' in the sequence that may be intrusive, or the tail-off of residual pottery beyond its main period of circulation. Quantification of pottery sequences is, however, rarely available in published reports.

Even when these points are taken into consideration, periodisation of a stratigraphic sequence is not an exact science; it is always an approximation, an attempt to impose an orderly chronological structure on what are in effect the results of sporadic and unstructured human activity. Periodisations should always, therefore, be open to criticism, review and revision as new evidence comes to light. For this reason, the material from a site should be published in enough detail for the reader to be able to re-assess the periodisation if required.

The above problems and considerations were taken into account when deciding the way in which the Paithan sequence was to be analysed and periodised.

\section{Periodisation of the Paithan sequence}

A total of seven trenches were excavated at Paithan during the 1996-1999 seasons (Trenches A, B, C, D1, D2, $\mathrm{E}$ and $\mathrm{F}$ ). Each of these provided a stratigraphic sequence reflecting the particular history of occupation in the part of the site where it was located. Only Trenches A:TP1, B,
D1, D2 and F were, however, fully incorporated into the site periodisation because the excavations in Trench C were notconducted by the present authors or according to the same system, and those in Trench E were exploratory and did not achieve great stratigraphic depth (see Chapter 5).

Taking into consideration the points that have been made above about the problems with the periodisation of Early Historic sites in India, careful thought was given to the best way of periodising the sequence from these five trenches. A number of datable objects or 'chronological markers' such as coins and sherds of known wares such as NBP and RPW are present in these sequences, but generally in very small quantities. The small quantity makes it very difficult to know whether or not any particular occurrence of such objects is residual, or indeed when they are absent, that the absence is not simply due to chance. It was therefore decided that such finds provide a very poor basis on which to correlate the five different trench sequences.

Instead, the periodisation was achieved through a combination of the quantified occurrence of known chronological markers: both the rarer examples such as NBP, RPW and glazed wares, as well as the more common examples such as Thick Grey ware (GREY) and Black and Red ware (B\&R) Type 38 - but this was linked to a quantified analysis of the occurrence through the sequence of the key pottery types defined at Paithan such as Types 7, 19, 32 and 37, the absolute dating of which is not known but whose occurrence through the stratigraphic sequences can be more precisely charted. The reason for this is that, in being very common, their absence in any particular layer can more reliably be taken as an indication they were not in circulation at the time that the layer was deposited. Consideration was also taken of the 'percentage occurrence profiles' of some of the more common types and wares through the sequence (see below). All of this relied on a much more precise definition of pottery wares and types than is normally the case at Early Historic sites in India (see Chapter 7). On this basis, the following four periods were defined. The absolute dating of each period is discussed in the following section.

The stratigraphic matrices for Trenches A, A:TP1, B, D1, D2 and F have been lodged with the Archaeological Data Service (http://dx.doi. org/10.5284/1017460). The matrix for the smaller trenches shows the occurrence of Types 7, 32 and 37, GREY and glazed wares. 


\section{Period 1}

In these layers, which occur in the lowest levels of all five trenches, a number of known chronological markers were found: 22 sherds of NBP occurred in eight out of 116 layers; 25 sherds of the very distinctive B\&R Type 38 were present in 14 layers and occasional microliths also came to light in some of the lowest layers of trenches D1 and D2, together with some rolled sherds of Jorwe ware. This period was also defined by the complete absence of the key pottery markers of Period 2, namely RPW and Types 7, 19, 32 and 37 (see below).

These same layers also contained a relatively high percentage of $B \& R$ generally. Although there is considerable variation, the percentage of B\&R Type 10 is consistently above $2 \%$ of the total sherd assemblage - in many cases much higher. The proportion of Type 1 can also be shown to have been increasing steadily throughout this period in each of the sequences (see below).

The lower part of the Trench $\mathrm{F}$ sequence has been allocated to this period on the basis of a single sherd of NBP and a high percentage of B\&R Type 10 .

There are three intrusive GREY sherds from layers attributed to Period 1 (see below).

\section{Period 2}

Of the 86 layers allocated to Period 2, only two contained sherds of RPW, both of which are from the Trench A:TP1 sequence. One sherd of NBP was also present in the same sequence, but this sherd was judged to be residual based on the presence of Types 19 and 32 in the same or in stratigraphically lower contexts.

The precise lower limits of the period are defined principally by the first occurrence of pottery Types 7 , 19, 32 and 37. These types are all reasonably common in the levels where they occur but none of them occur below approximately the same level in each of the trench sequences.

Type 7 is a very distinctive form. Its precise absolute date is unknown, apart from being broadly attributable to the later Early Historic period. It occurs in the sequences of trenches A:TP1, B, D2 and F, but it does not occur in the lowest levels of any of these trenches except $\mathrm{F}$, where it only occurs in layers stratigraphically later than the single sherd of NBP.

Type 19 occurs only in the Trench D2 and Trench A:TP1 sequences where it first occurs in levels very close to those where Types 7 and 32 first occur, suggest- ing that it was introduced into circulation at about the same time as these types.

Type 32 is the rim of a large storage jar. It occurs in the sequences from trenches A:TP 1, B, D1 and D2, in three cases (Trench A:TP1, B and D2) very close to the same level at which Type 7 first occurs.

Type 37 is a jar with an everted rim. It occurs in the sequences from trenches A:TP1 and D2 at very close to the same levels where Type 7 and the other types discussed here first occur.

There are a few later, intrusive objects in layers attributed to Period 2, including a porcelain peacock's head (No: 678) datable to the 16th century or later, and eight GREY sherds (see below).

\section{Period 3}

Period 3 is defined quite simply by the occurrence of the abundant GREY, Types 14, 15, 24, 26, 44, 45 and 46. This development is accompanied by a decline in the amount of Type 1 to below $5 \%$ of the total sherd assemblage in the trenches where the sequence continues this late (trenches A:TP1 and B). In fact, as mentioned above, three sherds of GREY are recorded from layers allocated to Period 1 and eight from layers allocated to Period 2. These are considered either mis-attributions or intrusive, that is to say, they were either erroneously recorded or they have made their way into early layers through soil disturbance of some kind. They have to be balanced against the 191 sherds of the same class that were found in the layers allocated to Period 3, and the 144 sherds in Period 4.

\section{Period '3-temple'}

Period ' 3 -temple' is used to differentiate those layers within Trench A that are datable to Period 3 but that are part of the construction and foundations of the two brick temples. These deposits do not result from domestic occupation and neither do they contain very much material. The artefactual and ecofactual assemblages from these layers are therefore likely to be of a very particular nature. Because they make up such a large proportion of the excavated layers presented in this report, it was thought to be sensible to keep them separate from Period 3 so that reliable comparisons can be made between the Period 3 assemblages and those from Periods 1, 2 and 4. 


\section{Period 4}

Period 4 is defined by the presence of late glaze wares such as Blue and White Frit (PERS), Slip-Painted Ware (SLIP) and Chinese Blue and White porcelain (CBW). These wares are not very common, and no other pottery types have been defined that can be used in association with them, thus making this period distinction perhaps the least reliable of those presented here.

\section{Period 4?}

'Period 4?' represents layers that were excavated in Trench A:NWNT which are clearly later than the abandonment and robbing of the temples and are most likely therefore to belong to Period 4, but there are no finds of glaze wares to demonstrate this unequivocally.

Further descriptions and discussions of the pottery types and wares can be found in Chapter 7, along with the relevant external dating evidence.

\section{Periodisation based on occurrence profiles of key types}

As has been stated above, there are various problems with using the presence of relatively rare datable finds such as coins and sherds of NBP or RPW as 'type fossils' with which to establish the periodisation of a sequence. One of these is that any one of these type fossils might be residual and the relevant layer might therefore be much later in date than some of the finds contained within it. A second problem is that the absence of a relatively rare find from any particular layer might be due to chance: it does not necessarily mean that the find was not in circulation when the layer was deposited. A third is what to do with those layers - often the majority - that do not contain any of the type fossils at all: which period should these be allocated to? These problems make it difficult to establish a reliable periodisation around what is often such a limited framework of datable evidence. The use of more common pottery types, such as those used above in the definition of Period 2, can help to reduce these problems, but they cannot resolve them entirely because of the paradox that the more common a type is, the more meaningful its absence from a layer is likely to be, but at the same time the more likely it is to occur residually in later levels.
One way to confront these problems is to calculate the percentage of the most common pottery types and wares as a part of the pottery assemblage and to use these figures as a comparative tool for aligning and periodising sequences. This was attempted at Paithan using Type 1, the most common single type from the site. Table 6.2 and Fig. 6.1 show the percentage occurrence of this type through the lower parts of the Trench B, D1 and D2 sequences - all of which are allocated to Period 1 as outlined above. There is a remarkable degree of correlation between the three sequences. Each of them contains percentages that are just under $10 \%$ in the lowest levels but which increase steadily to $25 \%$ and more towards the later Period 1 layers.

Of course, the percentage of a type in any particular layer or sequence is likely to be as much due to the activities that took place in the vicinity as it is to the chronological occurrence of the type, and these data must therefore be treated with some caution. Nonetheless, the pattern shown in Table 6.2 adds support to the periodisation that has been proposed.

\section{Trench A: phases of temple construction and use}

Within Trench A, the stratigraphy related to the construction and use of the temples was subdivided into architectural phases that are specific to each of the two temples and which have been described in detail in Chapter 4 . These are distinct from the periods that are defined and described in the present chapter.

\section{Absolute dating}

Chronology is still the most significant problem faced by archaeologists of the Early Historic and Early Medieval periods in India. The archaeological chronology of the Early Historic period of the western Deccan region is based largely on 1950s excavations by the esteemed H. D. Sankalia and his colleagues at sites such as Brahmapuri, Nasik, Maheshwar and Nevasa (Sankalia and Dikshit1952; Sankalia and Deo 1955; Sankalia et al. 1958, 1960). The dating of these sites is, in turn, based on earlier excavations at sites such as Arikamedu, Sisupalgarh, Brahmagiri, Chandravali and Taxila. The chronology that was established during this period has never been fully set out, critiqued and argued, but it has nonetheless become the received wisdom amongst archaeologists working in the region. 
Table 6.2: Percentage occurrence of Type 1 in the lower parts of the sequences from Trenches B, D1 and D2 (the top three rows show the context numbers as grouped for this calculation, and the lower three show the amount of Type 1 as a \% of the total sherd assemblage from those context groups).

\begin{tabular}{|c|c|c|c|c|c|c|c|c|c|c|c|c|c|c|c|c|c|c|c|c|c|}
\hline & 1 & 2 & 3 & 4 & 5 & 6 & 7 & 8 & 9 & 10 & 11 & 12 & 13 & 14 & 15 & 16 & 17 & 18 & 19 & 20 & 21 \\
\hline \multirow[t]{4}{*}{ B } & 743 & 736 & 733 & 494 & 497 & 493 & 492 & 487 & 486 & 485 & 484 & 483 & 478 & 479 & 477 & 474 & 473 & 472 & 471 & 469 & 468 \\
\hline & & 735 & 731 & & 498 & & & & & & & & & 480 & & & & & & 470 & \\
\hline & & & 734 & & 495 & & & & & & & & & 481 & & & & & & & \\
\hline & & & 732 & & 496 & & & & & & & & & 482 & & & & & & & \\
\hline \multirow[t]{8}{*}{ D1 } & 777 & & & 776 & & 770 & & 771 & & & 767 & & 766 & & & 760 & & 759 & & & 752 \\
\hline & & & & 775 & & & & 772 & & & & & & & & 761 & & & & & \\
\hline & & & & & & & & 773 & & & & & & & & 762 & & & & & \\
\hline & & & & & & & & 774 & & & & & & & & 763 & & & & & \\
\hline & & & & & & & & & & & & & & & & 764 & & & & & \\
\hline & & & & & & & & & & & & & & & & 765 & & & & & \\
\hline & & & & & & & & & & & & & & & & 768 & & & & & \\
\hline & & & & & & & & & & & & & & & & 769 & & & & & \\
\hline \multirow[t]{2}{*}{ D2 } & 729 & 727 & 726 & 725 & 722 & 723 & 721 & 719 & 718 & 716 & 715 & 713 & 712 & 711 & 710 & & & & & 709 & \\
\hline & & 728 & & & & 724 & & 720 & & 717 & & 714 & & & & & & & & 708 & \\
\hline B & 3.751 & 13.24 & 0.00 & 3.991 & 12.09 & 9.221 & 16.35 & 6.02 & 13.10 & 13.08 & 9.401 & 13.60 & 10.65 & 18.32 & 18.59 & 15.201 & 15.15 & 19.27 & 24.681 & 19.18 & 32.39 \\
\hline D1 & 10.34 & & & 2.30 & & 6.52 & & 18.75 & & & 11.15 & & 22.02 & & & 0.00 & & 30.56 & & & 33.33 \\
\hline D2 & 20.29 & 11.41 & 6.12 & 7.22 & 9.15 & 4.261 & 11.94 & 13.76 & 14.06 & 14.29 & 20.681 & 10.53 & 22.84 & & 19.67 & & & & & & \\
\hline
\end{tabular}

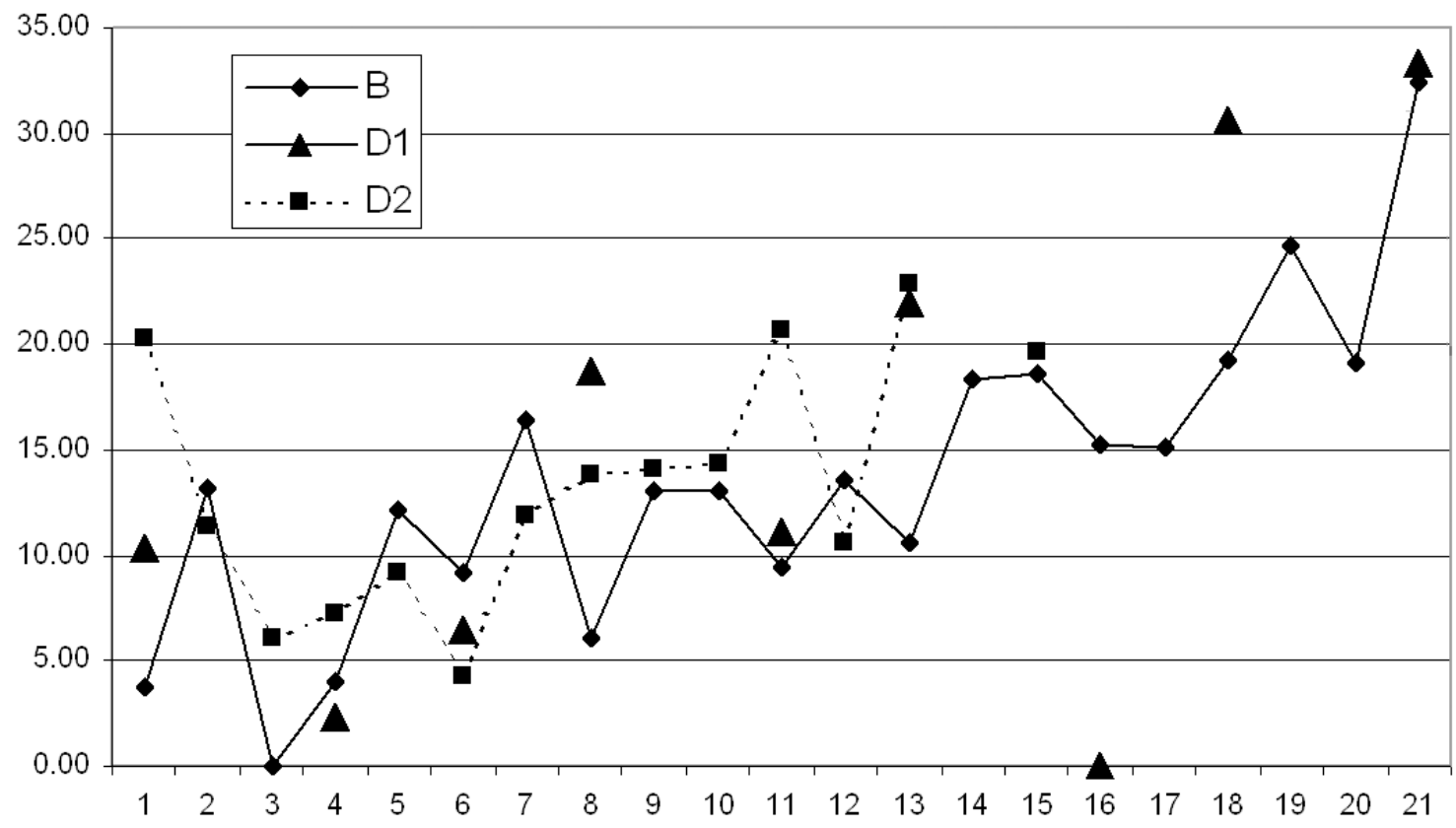

Fig. 6.1: Graph showing the percentage of Type 1 through the lower parts of the sequences from Trenches B, D1 and D2 (sherd count as \% of total sherd assemblage). 
It is, however, highly problematic and imprecise and is certainly now in need of thorough revision. The 'fixed points' are based almost entirely on identifications of coins, NBP, RPW and - at one or two sites - the presence of Roman amphorae. Other pottery wares, such as B\&R, Painted Andhra Ware and GREY, are also used, but these wares are not themselves independently dated other than through stratigraphic associations with the 'fixed points' listed above.

On examination, it becomes clear that the absolute dating of all of the 'fixed points' noted above can now be called into question for one reason or another.

Firstly, the dating of pre-Satavahana coins is, for the most part, still relatively imprecise and provides only the broadest chronological framework, whilst the classification and dating of Satavahana coins, although they have improved and changed since the reports mentioned above were published, are still subject to debate and disagreement (see for example Bhandare 1998; Gupta 1999). But the two most significant problems related to coins are residuality and the failure to take the concept of terminus post quem into consideration. These points are particularly important in a region where low-denomination Satavahana coins are known to have continued in circulation in large quantities until much later periods, whilst coins of later dynasties (e.g. the Vakatakas) appear to be very rare on most sites (see Chapters 9 and 14). This means that in some cases, post-Satavahana layers can contain nothing other than low-denomination Satavahana coins, which has led archaeologists to assign a date to such layers which is far too early, often by as much as 300 or 400 years. This fact may help to explain the apparent absence of Vakataka layers at many sites in the region.

Secondly, the chronological span of NBP has been established for the Gangetic region of India where, on the basis of $\mathrm{C}^{14}$ dates, it can be shown to have in production for as long as 500 years (see Chapter 7). Nonetheless, the date when NBP first began to occur in significant quantities in the western Deccan region is not known, neither is it known how long NBP continued to be used in this part of India or when its use finally died out.

Thirdly, there are also problems with RPW. The introduction of this ware is generally placed in about the 1st century $\mathrm{AD}$ and the ware is thought to have gone out of use between the 4th and the 6th centuries AD (Chapter 7). Although neither date is firmly established, however, production can now be shown to have continued until the 8th century AD through its occurrence on archaeological sites in the Arabian/ Persian Gulf (Kennet 2004a: 65-66).

Finally, at some sites such as Nevasa, the presence of Roman amphorae was used as dating evidence. Unfortunately, it has recently been shown that many of the Roman amphorae reported from India are, in fact, misidentifications of Mesopotamian 'torpedo jars'. These jars, although they are themselves quite imprecisely dated, are known to have continued in use and circulation beyond the 9th century AD (Kennet 2004a: 63; Tomber 2007).

The factors described above all demonstrate that the existing chronological framework for the Early Historic period in this region of India now needs to be carefully reviewed and the chronology proposed by the excavators of the sites mentioned above cannot be used as a reliable framework. This means that there is very little external evidence with which to establish the absolute dating of the Paithan sequence, which has therefore been based almost entirely on the 39 identifiable coins that were retrieved. The coins, which are presented in Chapter 9, were identified and dated according to the schema proposed by Bhandare (1998). The coins have been counted and tabulated so that patterns of occurrence and residuality are absolutely clear (see Chapter 9, Table 9.1).

In addition to the coins, there are two further elements of absolute dating, neither of which is very precise. The first is that provided by the temples themselves, which suggests that the North Temple was first constructed in the 4th or 5th century AD and the South Temple in the 6th or 7th (Chapter 4, Table 4.2). The second are two $\mathrm{C}^{14}$ dates taken from fragments of carbonized wood that were retrieved from the foundation deposits of each of the two temples (Table 6.3).

Both of the charcoal fragments, being datable to the 4th and 3rd centuries BC, are much older than the temple foundations, as is demonstrated by the coins from those layers and by the architectural dating of the temples, which has been mentioned above. At first glance, it might seem rather coincidental that the two charcoal fragments should give such similar dates, but it is obvious that the earth in the foundation deposits is likely to have been brought from the same source not far from the temples and will have contained artefacts and environmental material from earlier archaeological deposits. This issue is further discussed in relation to the coins in the foundation deposits in the Appendix to Chapter 9. 
Table 6.3: $\mathrm{C}^{14}$ dates from the temple foundations.

\begin{tabular}{|c|c|c|c|c|c|}
\hline Sample & Context & $\begin{array}{l}\text { Measured } \mathrm{C}^{14} \\
\text { age }\end{array}$ & $13 \mathrm{C} / 12 \mathrm{C}$ ratio & Conventional & 2 sigma calibration \\
\hline Beta 227163 & $\begin{array}{l}\text { North Temple } \\
(927)\end{array}$ & $2240 \pm 40 \mathrm{BP}$ & $-24.80 / 00$ & $2240 \pm 40 \mathrm{BP}$ & $390-200$ вС \\
\hline Beta 227164 & $\begin{array}{l}\text { South Temple } \\
(1002)\end{array}$ & $2280 \pm 40 \mathrm{BP}$ & $-25.50 / 00$ & $2270 \pm 40 \mathrm{BP}$ & $400-340$ and $320-210 \mathrm{BC}$ \\
\hline
\end{tabular}

Broadly speaking, the occurrence of coins through the sequence suggests the dates for the Paithan periodisation that are set out in the paragraphs below.

\section{Pre-Period 1: (1400-4th century BC)}

The rolled Jorwe sherds mentioned in Chapter 7 probably indicate a presence at the site roughly between 1400 and $700 \mathrm{BC}$ at the broadest level. Following this, no silver punch-marked coins of the Magadha-Maurya 'Karshapana' series were found in excavated layers, although seven are present in the Balasaheb Patil Government Museum at Paithan (Chapter 11, 1-7). These might indicate activity at Paithan as early as $370 \mathrm{BC}-\mathrm{a}$ date which tallies with the earlier end of the date range of the $\mathrm{C}^{14}$ dates reported above - but, as the precise find spots of these coins are not known, it is impossible to be certain that they were originally found at Paithan.

\section{Period 1: Pre-Satavahana (200-100 BC)}

The eight pre-Satavahana 'hollow cross' type coins retrieved from levels of this period can be dated between 200 and $100 \mathrm{BC}$ (Chapter 9). These are the earliest coins that came to light from the excavations. Technically, of course, they provide only a terminus post quem but, because eight such coins were found in these levels and no later coins were found with them, despite the fact that later coins can be shown to have been deposited in later layers at the site in quite large quantities, this dating can probably be taken as being reasonably reliable (see Chapter 9, Table 9.1).

\section{Period 2: Satavahana (late 1st century BC to late 1st century AD although possibly as late as the 4th century AD)}

All of the 18 identifiable Satavahana coins found at Paithan can be dated to the immediate pre- and postGotamiputa Satakani period suggesting activity at the site between the late 1st century BC until the late 1st century AD. The absence of coins actually attributed to Gotamiputa Satakani's reign (e.g. AD 55-79 or 66-90; Cribb 1992: 134; Bhandare 1998) is, however, notable. This absence might indicate that all or part of the site was abandoned through his reign, but it seems more likely that it results from a change in the pattern of coin circulation or deposition during the same period. At the same time, it is important to note that only one Satavahana coin (Chapter 9, coin 17) was actually found in the excavated layers of this period, along with two earlier 'hollow cross' type coins. The latter are clearly residual, but it should nonetheless be noted that, although the layers of Period 2 are likely to have been deposited during the late 1st century BC to late 1st century AD period (a period during which activity at the site is suggested by the coins that have been found in later layers), it is of course quite possible that coin 17 is residual and that the layers of Period 2 were actually deposited at a somewhat later date. This must have been before the 4th/5th century, as is shown by the stratigraphic relationship with Period 3 levels, but it could just as easily have been in the 2nd to 4th centuries AD.

\section{Period 3 and Period 3-temple: post-Satava- hana (4th/5th to 8 th century AD)}

The dating of Period 3-temple is provided by three pieces of evidence:

- the 4th/5th century AD architectural dating of the earliest construction of the North Temple; 
- the 6th/7th AD architectural dating of the construction of South Temple (Chapter 4) and

- the latest of the two post-Satavahana coins in the South Temple foundation deposits (Chapter 9, coins 33 and 34), which is probably also datable to the 7th century AD (whilst the earlier of these two coins is obviously residual). The end of the period has been dated to about the 8th century AD but this is based largely on an estimation of how long the temples may have remained in use and is not reliable.

The dating of Period 3 is slightly more complicated. Analysis of the pottery indicates that it is contemporary with Period 3-temple, but post-Satavahana coins are only present in Period 3-temple levels. This is almost certainly due to the fact that, because post-Satavahana coins are much less common than Satavahana coins, they are generally found only in larger assemblages, but it does leave open the possibility, as does the stratigraphic sequence, that some Period 3 deposits were deposited somewhat earlier.

There appears to be no reliable evidence for the dating of the introduction of the so-called 'Early Medieval' grey wares (GREY) from the publication of any other excavated site. These wares are often suggested to have begun to circulate in the 8th century $\mathrm{AD}$, but, if the dating of the Northern Temple here at Paithan is reliable, they can be shown to have been in circulation at Paithan by the 4th or 5th century or shortly thereafter.
It will be noted from the discussion above that there is no clear evidence from the excavations for activity between the end of the 1st century and the 4th/5th centuries AD. Again, this apparent void may be due to a decline in activity over all or part of the site, but it may also be due simply to a change in the pattern of coin circulation or deposition during this period.

\section{Period 4: 14 th/15th to 17 th century and later}

On the basis of the coins, Period 4 can be dated to the Late Medieval and British periods. Some of the pottery found in Period 4 levels, e.g. Blue and White Frit (PERS), might suggest that this rather loosely defined period encompasses activity as early as the 14th century, but the majority of datable finds such as coins and imported Chinese porcelain can be dated to the 15th to 18th centuries.

The apparent lack of activity between the abandonment of the temples and the 14 th/15th centuries is something that has been noted at many sites. It is possible that occupation moved or contracted to a core that is now buried underneath the modern town of Paithan during this time. The relatively limited investigation of layers of this period does not allow further discussion of this point. 